\title{
ESTRATEGIAS SEMIOLINGÜÍSTÍCAS EN EL DISCURSO PUBLICITARIO GRÁFICO DEL PERFUME ESPAÑOL (AÑOS 50-90)
}

\author{
Lidia PELLICER GARCÍA \\ Universidad de Murcia \\ lylipellicahotmail.com
}

Resumen: El significado del signo olfativo del perfume español se genera en el discurso publicitario gráfico a través de la función configurante sintácticosemántica que ofrece la narratividad, de la que surgirá la acción y el conflicto de valores, logrando la identidad de marca.

Abstract: Olfactory sign's meaning about spanish perfume is generated in the advertising graphic speech, through the configuration syntactic-semantic that narration offers, arising the action and the values conflicts, obtaing brand identity.

Palabras clave: Significado. Signo. Discurso publicitario. Acción. Valor.

Key Words: Meaning. Sign. Advertising Speech. Action. Value. 


\title{
1. LA IRREPRESENTABILIDAD. LAS PRIMERAS AGENCIAS PUBLICITARIAS TRAS LA POSGUERRA ESPAÑOLA
}

\author{
Todo signo parece muerto. \\ ¿Quién les da la vida? \\ Wittgenstein (1998)
}

¿Cómo expresar un olor? ¿Cómo crear la significación de un signo olfativo mediante un signo visual y construir una sensación, una percepción, una memoria olfativa identificativa?

S. Madrid (2007) ha recopilado un corpus sobre el perfume, cuyo movimiento arranca en el año 1950 y se detiene en el año $2000^{1}$. Como toda historia, la vida del perfume requiere de un andar que carece de residencia fija, que vaga, que es errante, pero que finalmente, en su devenir cambiante, se transformará en señal, en signo.

¿Cómo se construye el significado del perfume en este movimiento? ¿Cuál ha sido su vida? En su génesis nos encontramos con el primer obstáculo: la irrepresentabilidad. En los años 50-60 la idea del perfume no estaba ligada a un producto de consumición concreto, sino que se concebía como un elemento multiuso unido a la crema o al jabón. Lo importante era limpiar y perfumar económicamente, dejando a un lado la presencia de perfumes y colonias exclusivas para la mujer. Por tanto, la familia, lo doméstico y lo práctico corren de la mano de la publicidad de estos años.

Hemos de tener en cuenta, como señala Madrid (2007: 83-84), que nos situamos en el periodo de la posguerra española, periodo que queda marcado por la palabra crisis, ya que la crisis mundial que se inicia en el año 1929, junto al estallido de la guerra civil, supuso el hundimiento de las posibilidades expansivas de su industria y la quiebra del que parecía el despliegue definitivo de la economía española. El primer franquismo encauzó dicha economía por la senda de la autarquía, hasta que, en la década de los cincuenta, se produce una motorización del país y una primera modernización del mismo. Las agencias publicitarias heredan la dificultad de instalar la publicidad española de veinte años de retroceso en la vida social y económica. Las agencias más comunes son simples corredores de anuncios que van y vienen desde los periódicos. No hay muchos anunciantes importantes, ni, en consecuencia, agencias expertas.

\footnotetext{
${ }^{1}$ Las tres figuras seleccionadas en este trabajo pertenecen a dicho corpus.
} 


\section{LA NARRATIVIDAD COMO SIGNIFICATO D'INSIEME. LA SEMIÓTICA DE LA ACCIÓN. LA ATRIBUCIÓN LOGICISTA DEL PRODUCTO. LA VALORIZACIÓN PRÁCTICA. LO NECESARIO (AÑOS 50/60)}

¿Cómo descifrar la significación de un anuncio publicitario? Fabbri (1998: 24) destaca que la narratividad tiene una función configurante, en la que el plano de la expresión y el plano del contenido actúan conjuntamente en la elaboración del proceso significativo²:

L'idea è che la narratività è una maniera di mettere in movimento la significazione combinando in maniera specifica non soltando parole, e neanche frasi e proposizioni, ma speciali «attanti» sintattico-semantici che poi semanticamente investiti a livello discorsivo diventano attori, personaggi e cosí via. La narratività ha una funzione configurante, rispetto a un racconto dato, rinviando d'acchito a un significato d'insieme.

De ese significato d'insieme surge la acción, la cual es la que transforma, la que modifica, como apunta Humboldt (1836) y señala Fabbri (1998: 24):

Cosí, la nozione di narratività fa della semiotica innanzitutto una teoria dell'azione, la quale, in fondo, nel momento stesso in cui modifica radicalmente il paradigma semiótico di Barthes o di Eco, riprende una vecchia idea della storia della linguística, risalente per esempio a Humboldt. È l'idea secondo cui il linguagio non è fatto per rappresentare stati del mondo; esso è azione e serve semmai a trasformare quegli stati, modificando al tempo stesso chi lo produce e chi lo comprende. Ipotesi cosí fondamentale che se non ne teniamo conto rischiamo di continuare a pensare, in modo affatto sterile, il linguaggio come un problema di rinvii e di giochi di specchio.

A este respecto, Semprini (1995: 39) afirma que es en la narración donde las constantes son puestas en el relato, organizadas en lugares de acción, construidas según la lógica de los escenarios, utilizando estratégicamente la división del relato en episodios para crear un suspense, un mecanismo narrativo particular basado en la alternancia de tensión y distensión. De esta forma, la estructura narrativa contribuye a la creación significativa del discurso de la marca, a la vez que a la presencia de un conflitto di valori: «le narrazioni sono sempre intrise di valore» (Volli, 2003: 81).

\footnotetext{
${ }^{2}$ Véase U. Volli (2003: 77-81) y P. Magli (2004: 68-69).
} 
Veamos cómo se configura la acción valorial en su diacronía en torno a la publicidad gráfica del perfume español, haciendo caso de la afirmación de Greimas (1975), recogida por Magli (2004: 181): «è nei testi a partire da essi che si deve interrogare la teoria delle passioni». En primer lugar, como fruto del contexto de motorización, nos encontramos con unos programas narrativos caracterizados por la atribución básica y lógica del producto. En la figura I del anexo encontramos una muestra de lo que venimos diciendo; en el anuncio observamos la domestización de las fragancias naturales del campo encarnadas en el jabón y en el agua de Lavanda.

Ambos tendrán un mismo destino: el hogar como cuerpo en el que los productos-objetos serán utilizados de manera práctica y económica. De esta forma asistimos a lo que Floch (1990) denomina valorización práctica del objeto, definida por Marrone (2002: 17) como «una valorizzazione pratica, con la quale si considera l'oggetto sopratutto per il suo carattere di strumento», esto es, una valorización en la que se considera el objeto sobre todo por su carácter de instrumento, desarrollando, de esta forma, la pasión de la necesidad.

¿Cómo se figurativiza este hogar? Mediante unas cortinas de ducha y una toalla. El formato del anuncio es, como puede comprobarse, de estructura cuatripartita, formada por dos rectángulos icónicos y dos verbales, adquiriendo más espacio narrativo el nivel visual que nos predica automáticamente el concepto de limpieza; concepto figurativizado en la escena en un actante sujeto cuya acción es mostrar el objeto necesario de la higiene personal: el jabón. Su fragancia se mezclará con las flores estampadas de las cortinas de la ducha (como metonimia, a la vez que anáfora, de la Naturaleza para focalizar, mediante la imagen, el texto verbal las fragancias naturales del campo) y envolverá con suave caricia el cuerpo que necesita la higiene. De esta forma somos testigos de la identificación metafórica de la mujer-colonia, envuelta posteriormente por otro miembro del hogar: la toalla, en otro momento de higiene personal: la caricia de la colonia con el mismo olor floral a Lavanda.

Como vemos, la construcción del significado «perfume» figurativiza el concepto higiene en la personificación femenina hogareña, donde el cuerpo humano centraliza la escena, creando una pasión de necesidad en el usuarioconsumidor, sin que ello provoque el deseo de la pasión escópica ${ }^{3}$, como

${ }^{3}$ Gonzalo Abril (2007) destaca tres niveles que constituyen la experiencia visual: lo visual, la mirada y la imagen. En el nivel de la mirada sitúa la pasión escópica, característica de la mirada compulsiva o anhelante del usuario-consumidor. 
destaca Abril (2007); esto es, nuestros ojos no se abren al deseo, a la identificación, a la exclusividad, al querer ser, etc., tan sólo experimentamos en la acción la necesidad de ser limpios y oler bien, ora usando una colonia, ora una crema o un jabón. Por tanto, domesticidad, limpieza, higiene y practicidad en torno al universo del sujeto en escena que todavía no se ha constituido en un sujeto-marca capaz de apropiarse o restar valores a la competencia. La narratividad sintáctico-semántica se limita a mostrar un producto todavía objeto (que no signo, pues todavía no hay representación de un mensaje de identidad), ensalzando algunas cualidades. Con todo, S. Madrid (2007: 123) señala dos conclusiones:

1. La desposesión del valor de la feminidad en estos productos.

2. La in-competencia del sujeto hacedor de los anuncios de perfumería masculina, un no saber-hacer, que implica un destinatario lector femenino en la función pragmática.

No obstante, tendremos que esperar unas cuantas décadas para visualizar procedimientos textuales que permitan crear el significado de la irrepresentabilidad.

\section{LOS PRIMEROS ESCARCEOS DE LA EMOTIVIDAD. LA VALORIZACIÓN UTÓPICO-SOCIAL. EL DESEO (AÑNOS 60/70)}

Emoción, pasión, ritmo... Todo queda excluido en este momento de la vida del perfume, no hay perspectiva relevante que incite al co-enunciatario a desear el objeto de un anuncio. El único rastro emotivo lo hallamos en una cierta estética americana o anglosajona seductora de los personajes que aparecen en escena, como podemos observar en la figura II.

¿En qué se diferencia este anuncio del anterior de Lavanda? Precisamente, en los referentes sociales. Mientras que en el discurso de Lavanda se visualizaba la imagen de la recatada lozanía española, en esta ocasión podemos vislumbrar otro cuerpo: el estereotipo de la insinuante rubia platino norteamericana. Sin embargo, lo verbal no deja de transmitirnos cualidades lógicas del objeto. En ambos discursos aparece representado verbo-icónicamente el mundo de lo floral, siendo enfatizado (también en ambos anuncios) el plano icónico mediante la repetición anafórica de la pluralidad floral, cuyo aroma siente visualmente el consumidor y el actante sujeto figurativo, 
el cual muestra una acción emotiva que no parece indicarnos únicamente el sentir de un buen olor.

La acción discursiva nos muestra una independencia del objeto con respecto a la figuratividad hogareña (la crema y el jabón), desarrollando una atribución narrativa más característica. Así, por ejemplo, en este anuncio nos topamos con la cualidad de la audacia representada, incluso en su movimiento, coincidiendo con el nombre propio de la colonia «Cocaína», nombre al que «audazmente» se asocia. Utilizar estas estrategias discursivas supone una ruptura con respecto a la predicación lógica del perfume de la etapa anterior, una separación de la valorización práctica del producto para pasar a lo que Floch (1990) denomina valorización utópica ${ }^{4}$, definida por Marrone (2002: 17) como «una valorizzazione utopica, mediante la quale il soggetto realiza la propia identità congiungendosi con il suo oggetto di valore»; valorización en la que el sujeto realiza su propia identidad, conjugándose con su objeto de valor accediendo a la pasión del deseo.

Dicha valorización utópica se extiende hasta la propia performanza del envase, pues asistimos a una metamorfosis del mismo, pasando de lo amorfo y estándar a la figuratividad de la feminidad y el placer representada en el rostro de la chica, punto de referencia del creador para esculpir lo que será un producto exótico y delicado. Por tanto, una nueva etapa se abre ante los ojos del espectador: la etapa del desear la identificación con el cuerpo estereotipado.

La publicidad, como vemos, aún no muestra emociones, pero comienza a experimentar con las del receptor de sus mensajes, mostrando a aquellos héroes con los que el co-enunciatario ansía identificarse. Lo mismo les sucederá a los consumidores potenciales masculinos que encontrarán su referente en una representación actorial que responde al patrón de lo que conocemos como dand $y^{5}$; referente que encontraremos en todos los anuncios de la época independientemente de la marca o el tipo de producto (jabón, loción, colonia).

Por tanto, como señala Madrid (2007), en esta etapa de los años 50/70 las estrategias textuales del perfume oscilan, por un lado, entre los planteamientos informativos y prácticos que sumergen el producto en un universo

\footnotetext{
${ }^{4}$ Hemos de tener en cuenta que J. M. Floch (1990: 175) define el término utópico de forma independiente al sentido ilusorio: «Utopico non è qui da prendere nel senso illusorio, ma proprio nel senso di tensione finale (ideale). Si chiama spazio utopico, in semiotica narrativa, lo spazio dove l'eroe si realizza, il luogo dove effettua la propia performanza».

5 S. Madrid (2007: 123) destaca que Varón Dandy, de la casa Parera, se comercializó por primera vez en 1919, con un original frasco con forma de gentleman.
} 
de la limpieza y la higiene y, por otro, entre los que apuntan narrativamente a valores utópico-sociales del producto, manifestados con la escasez de medios gráficos de la época, pero rozando el umbral de lo mítico; umbral que hace que el discurso publicitario tome impulso, especialmente en los años $60 / 70$, pues en estos años se produce un hecho determinante para muchos órdenes de la sociedad moderna, pero, sobre todo, para la expansión del mensaje publicitario en España: la consolidación de la televisión.

\section{DEL OBJETO AL SIGNO MÍTICO ELOCUENTE. LA VALORIZACIÓN LÚDICO-ESTÉTICA. EL PLACER (AÑOS 80/90)}

El producto-objeto sigue su caminar utópico y, de esta forma, llegamos a la década de los 80, en la que la imagen irá adquiriendo, poco a poco, una mayor fuerza narrativa, focalizando sus principales valores significativos, con lo cual la imagen pasará a ser considerada físicamente como un elemento más del complejo sistema social de la moda, del vestir cotidiano, del estilo personal y, en definitiva, del consumismo producido, entre otros factores, por la caída del régimen franquista, la reestructuración de la actividad de la población y el consiguiente aumento del volumen productivo en el sector servicios y la industria; un mayor nivel de vida medio, así como una estimulación gubernamental para aumentar el consumo privado y las importaciones. Todo lo cual ratifica la incursión masiva de perfumes extranjeros, fundamentalmente franceses.

Actividad, producción, consumo, competencia: identidad. A este respecto, Klein (2005: 34) señala lo siguiente:

Lo que diferenció los primeros intentos de imponer marcas de la comercialización corriente fue el hecho de que el mercado se vio inundado con productos fabricados en masa y casi idénticos entre sí. En la era de las máquinas, la competencia por medio de las marcas llegó a ser una necesidad: en un contexto de identidad de producción, era preciso fabricar tanto los productos como su diferencia según la marca.

De esta forma surge lo que ella denomina el significado esencial, el alma, la identidad, de tal forma que el objeto cede paso a la creación del signo, a la imagen de marca, experimentando una nueva valorización: la lúdicoestética (Floch, 1990), definida por Marrone (2002: 17) como la valorización en la que se considera el objeto, prescindiendo de su utilidad, a partir de las 
cualidades formales y físicas, las cuales proporcionan el placer y la belleza desatando en el co-enunciatario la pasión del capricho:

Una valorizzazione ludico-estetica corrispondente alla negazione di quella pratica, dove si considera l'oggetto, prescindendo dalla sua utilizzabilità, a partire dalle sue qualità formali e fisiche, del piacere che procura, dalla sua bellezza.

En este sentido, el discurso de marca nos muestra cómo la eufonía del nombre del perfume, junto a la sugerencia toponímica y los estereotipos culturales, cumplirá, además, la función connotativa de crear un género y, por ende, un sexo a la marca. Veamos un fruto de estas circunstancias en la figura III.

Como puede verse, lo mítico y los valores identificativos, que habían sido destapados en la década de los 70, cada vez cobran más auge. En esta década, el valor lúdico-estético de sofisticación es lo que vertebra el mensaje de marca. No obstante, para crear ese significado de identidad es necesario un nombre, como señala Klein (2005: 35), el cual le otorga un alma al producto identificativo: «Me gusta pensar que la publicidad es algo grande, espléndido, que penetra profundamente en las instituciones y llega hasta su alma [...]. Las empresas tienen alma, tal como la tienen las naciones y los hombres» ${ }^{6}$.

Así, frente a lo abstracto e impersonal de la industria, la firma se alza como persona verdadera y propia, garantizando la continuidad de un estilo, la permanencia de unos valores, de ahí que sea lo primero que encontramos en este anuncio. Una vez hecha la carta de presentación, nos topamos con un destinatario genérico pour homme, que no señala a un hombre cualquiera, sino a aquellos que sienten, que se identifican con el valor lúdico-estético que irradia tanto el plano icónico como el verbal. Empecemos por analizar el contenido verbal que, como vemos, queda arrinconado por la imagen. La figuratividad escogida para transmitir estos valores ha sido la de ruptura de la linealidad. Estamos ante una oración en francés, deshuesada en cuatro sintagmas, de los cuales tres son nominales, a excepción de uno verbal en el corazón de la oración. Todos apuntan hacia la imagen del envase del signo, cuyo significado es el siguiente: Eau sauvage / decouvrez / le charme discret / de l'elegance (agua salvaje / descubra el encanto discreto de la elegancia) ${ }^{7}$.

${ }^{6}$ Naomi Klein (2005: 35) destaca la intervención de Barton en 1923 al presidente de GM, Pierre Du Pont, en la cual se explica que el papel de la publicidad era ayudar a las grandes compañías a encontrar su alma.

7 La traducción es mía. 
Salvaje, encanto discreto, elegancia. Ya no estamos ante la descripción de las cualidades lógicas de una colonia. La pasión necesaria objetual de las primeras décadas se ha transformado en pasión caprichosa y placentera del signo, cuya posesión significa adquirir todas sus cualidades significativas: elegancia, encanto, discreción... significa ser un hombre Dior.

Al igual que sucedía en los años 70, esas asociaciones intersensitivas las encontramos, además, en el vendedor mudo, el envase, como manifiesto visual ante un líquido que, físicamente, sólo se distingue por una mayor o menor tonalidad ambarada. El tamaño, la geometría, el material y el color se encargan de representar la concepción sensitiva del producto. De esta forma, el signo olfativo adquiere una corporeidad estética que lo convierte en un objeto de colección $\mathrm{y}$, en consecuencia, en un objeto de seducción. Corporeidad que queda representada en nuestro caso de dos maneras: una natural, mediante un frasco con formas geométricas cuadradas y otra metafórica, mediante la creación del estereotipo del hombre Dior, cuya figura cuadrada se identifica con la forma del envase. No obstante, frente a esta repetición enfática, nada es en vano, pues mientras que el envase aparece descubierto, el hombre-envase está semidescubierto, destapando sensaciones lúdicas de encanto discreto, de discreción, de elegancia, evitando el salvajismo y la animalidad del erotismo. Observamos cómo hay un perfecto anclaje entre lo verbal y lo icónico para crear un mismo significado, un nuevo valor, un nuevo signo: el perfume Dior. Prueba de ello es la utilización de la dilogía en el lenguaje (descubierto) y la identificación metafórica.

Dentro de esta identificación, nos topamos con la caja del producto-signo, cuya correlación semántica la hallamos en la figuratividad de una toalla y un albornoz; ambos instrumentos de higiene personal que nos retrotraen en el tiempo a las estrategias de valorización práctica del primer anuncio de La$v a n d a$, en el que también encontrábamos utensilios de higiene personal. No obstante, observamos una gran diferencia entre los dos anuncios, pues ahora la imagen adquiere el rol de héroe de la acción, apropiándose del valor del producto para transformarse en un signo-marca, frente a lo que ocurría en el discurso de la primera etapa, en el que se manifestaba como un mero instrumento portador del objeto-producto, caracterizado por la necesidad y rigidez emotiva. En este último anuncio, el hombre Dior portará como complemento más de su encanto discreto, el perfume situado en el bolsillo de ese albornoz, de esa caja, de esa elegancia. Por tanto, es el portador de la elegancia que lo cubre, desde su corazón (al igual que el verbo descubrir en la oración inicial), quedando así descubierta ante la mirada del co-enunciatario. Todo en él es elegante: su postura en escena, su manera de sostener la toalla, su mirada, su sonrisa, la posición del perfume, su elección de la marca. 
Vemos, pues, cómo el discurso de la marca deposita en la imagen la casi totalidad del mensaje transmitido, cuya naturaleza es fuertemente estética, delegando, así, las labores más comerciales al apartado verbal (la marca y la empresa) y depositando todos los valores en la expresividad corporal como lugar en el que se despliega la emoción.

\section{CONCLUSIONES}

El vagar errante del objeto «perfume» en la publicidad gráfica del perfume español ha experimentado cambios en la producción de su significación, pasando de la valorización práctica en los años 50/60 - en los que se hacía necesario exponer el producto ante la sociedad de manera básica - a la valorización utópica de los años 60/70, donde la acción discursiva despliega en el co-enunciatario la pasión del deseo de referentes sociales, para terminar en la valorización lúdico-estética de los años 80/90, en la que el significado discursivo se focaliza en la imagen elocuente, donde lo necesario de antaño se torna en placer, produciendo, de esta forma, el efecto deseado, representando lo irrepresentable, donde el cuerpo se hace signo-portador del perfume, encarnando, como alegoría humana, cualidades de la personalidad ansiada o identificada con el sujeto-consumidor, guiándolo además en la percepción de una imagen de marca concreta, a través de la mirada, en donde ese cuerpo ajeno nos sobredetermina, cargándonos de intencionalidad y de modelización subjetivas: las del capricho y el placer.

El cuerpo ajeno se ha hecho cuerpo elocuente, pues remite a la representación, a la cargazón epistémica, estética y simbólica de la experiencia visual, al orden del imaginario, al signo, logrando una identidad de marca, un alma propia.

\section{REFERENCIAS BIBLIOGRÁFICAS}

ABRIL, G. (2007). Análisis crítico de textos visuales. Mirar lo que nos mira. Madrid: Síntesis.

FABBRI, P. (1998). La svolta semiotica. Roma-Bari: Laterza.

FLOCH, J.M. (1990). Semiotica del marketing e comunicazione. Dietro $i$ segni, le strategie. Milano: Tipomoza. 
GREIMAS, A. (1975). Maupassant. La sèmiotique du texte: exercises pratique. Paris: Seuil.

HUMBOLDT, W. (1836). La diversità delle lingue. Roma: Tipomoza.

KLEIN, N. (2005). No logo: el poder de las marcas. Barcelona: Paidós.

MAGLI, P. (2004). Semiotica. Teoria, metodo, analisi. Venezia: Marsilio.

MADRID, S. (2007). Los signos errantes. Estrategias de la publicidad gráfica española 1950-2000. Murcia: Cendeac.

MARRONE, G. (2002). La società degli oggetti. Problemi di interoggettività. Roma: Meltemi.

SEMPRINI, A. (1995). Le marque. Paris: Presses Universitaires de France.

VOLLI, U. (2003). Semiotica della pubblicità. Roma-Bari: Laterza.

WITTGENSTEIN, L. (1998). Investigaciones filosóficas. Barcelona: Grijalbo.

\section{ANEXOS}

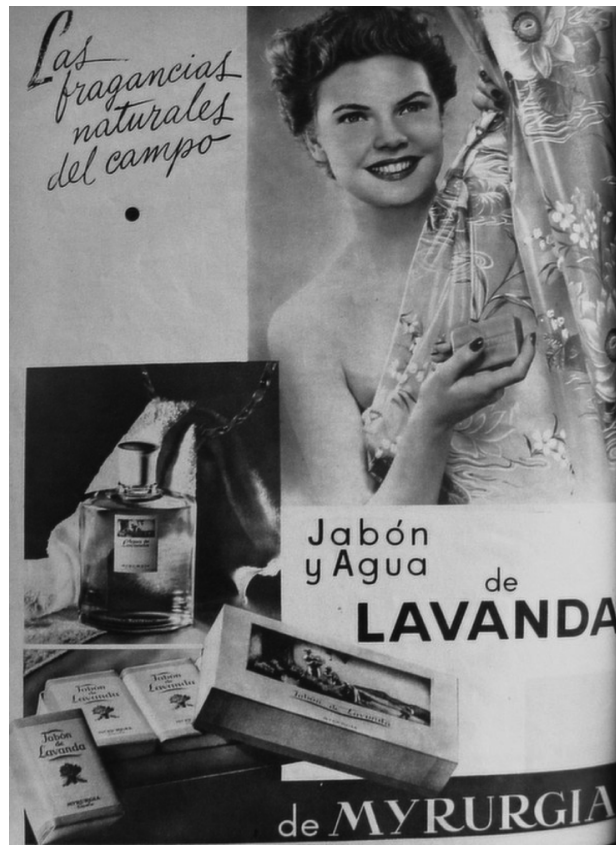

Figura I. España años 50. Valorización práctica. 


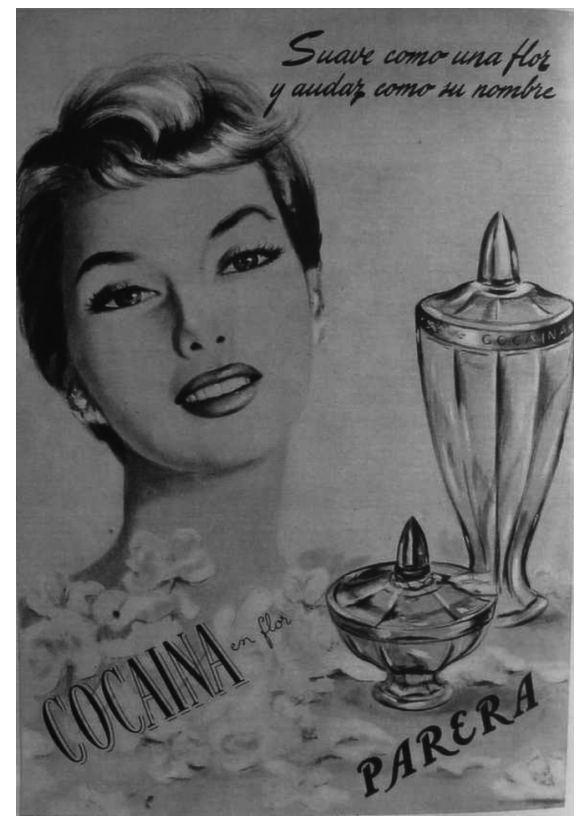

Figura II. España años 70. Valorización utópica.

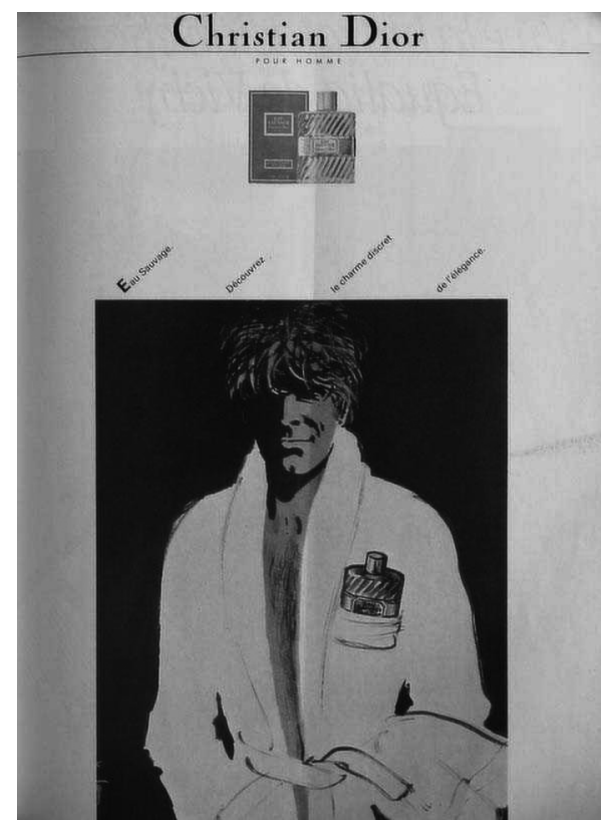

Figura III. España años 90. Valorización lúdico-estética. 